\title{
Levels, Trends and Determinants of Infant Mortality in Nigeria: An Analysis using the Logistic Regression Model
}

\author{
Donalben Onome $\mathrm{Eke}^{1,{ }^{*}}$ and Friday Ewere ${ }^{2}$ \\ ${ }^{1}$ Department of Statistics, University of Benin, Benin City, Edo State, Nigeria \\ e-mail: donalben.eke@physic.uniben.edu \\ ${ }^{2}$ Department of Statistics, University of Benin, Benin City, Edo State, Nigeria \\ e-mail: friday.ewere@uniben.edu
}

\begin{abstract}
This paper presents a statistical analysis of the levels, trends and determinants of infant mortality in Nigeria using the logistic regression model. Infant mortality data for each of the five years preceding the 2003, 2008, 2013 and 2018 Nigeria Demographic Health Survey (NDHS) was retrieved and used for the analysis. Findings from the study revealed that infant mortality rates decline have stagnated in the five year period prior to the 2018 survey with an Annual Rate of Reduction (ARR) of $0 \%$ relative to an initial ARR of $5.7 \%$ between 2003 and 2008. The ARR of $2.039 \%$ over the 15 year period spanning 2003 to 2018 suggests that the rate of infant mortality reduction is slow. This study also showed that maternal characteristics such as age and educational levels as well as cultural practises like use of clean water and toilet facilities were statistically significant determinants of infant mortality in Nigeria with $P$-values $<0.05$ across each of the survey years.
\end{abstract}

\section{Introduction}

The call to end preventable childhood death was one of the glaring targets of the Millennium Development Goals (MDG). Tasked with the mandate of reducing global childhood death by two-thirds before the year 2015, many countries in Asia and Africa failed to meet the target and subsequently, the Sustainable Development Goals (SDG) were rolled out signifying a recommitment to the health of mother and child during the different stages of childhood development [21]. On a global level, the world has

Received: August 29, 2021; Accepted: October 1, 2021

2020 Mathematics Subject Classification: 62-XX.

Keywords and phrases: infant mortality, logistic regression, child health, trends, Nigeria.

*Corresponding author

Copyright (C) 2022 the Authors 
continued to press in the right direction and many countries in Europe and America have made steady progress over the years with respect to childhood mortality reduction [4]. Despite the global record of improved childhood survival and reduced average mortality rate as seen by the rise in the Annual Rate of Reduction (ARR) from $1.9 \%$ in the year 2000 to $3.5 \%$ in 2015 [12], [13], [8], childhood mortality at all levels are still unacceptably high and significantly distributed unevenly among the different regions, continents and countries with countries such as India, Bangladesh and Nigeria to mention a few in Asia and Africa still recording ridiculously high and unacceptable rates of neonatal, post neonatal, infant, under-five and childhood death [6], [2], [9]. The different stages of childhood mortality continue to respond differently to the various prevention and intervention programmes of the United Nations with the rate of reduction in under-five mortality being the most significant of all the reported reductions in childhood mortality (National Bureau of Statistics [15], [19]). Results from previous studies have shown that a significant proportion of under-five mortality occurs at the neonatal and infant stages of the child's life [11], [17], [16], [20]. In 2018, approximately 5.3 million children across the globe lost their lives mainly due to preventable causes before their fifth birthday of which 1.5 million children accounting for $29 \%$ of under-five deaths died as infants [21].

It is therefore imperative for stakeholders in public health sector to focus attention on mortality of children occurring during the stage of infancy. Infant mortality defined as the probability of a child dying between birth and the first birthday [22] is relevant to the demographic assessment of a country's population and is an important indicator of the country's socioeconomic development and quality of life. It can also help identify children who may be at higher risk of death and lead to strategies to reduce this risk [21], [18].

In Nigeria, studies have shown that the rate of reduction in infant mortality relative to under-five mortality is poor indicating that less progress have been made in the fight against childhood mortality occurring within the first year of life [5], [1], [14], [7]. Given the percentage of under-five deaths that occurs during the first year of life, Nigeria is faced with the danger of failing to attain the SDG for childhood mortality except it implements and rigorously pursue drastic measures aimed at a substantial and corresponding decrease in infant mortality [10]. To achieve the childhood mortality target in responds to the call to end preventable deaths and give our infants a chance to live (which is a fundamental right), a good understanding of the current levels and trends as well as the significant determinants of infant mortality is necessary to monitor progress 
and required to help policy makers/relevant stakeholders make informed decisions on effective prevention/intervention programmes.

Having painstakingly searched through relevant articles and journals via the internet, this study, to the best of our knowledge is the first to utilize a nationally representative data from four consecutive Nigeria Demographic and Health Surveys (NDHS) for the modeling and analysis of the levels and trends of infant mortality in Nigeria for each of the five years period prior to the 2003, 2008, 2013 and 2018 surveys (20 years) and its implication for the achievement of the SDG for childhood mortality by 2030. The aim of this study is therefore to (i) carry out an analysis of the levels and trends in the age at death distribution of infants in Nigeria over a longer time frame with a view to assessing the progress in the reduction of infant mortality (ii) broaden insights into the significant determinants of infant mortality necessary to achieve the SDG for childhood mortality in Nigeria.

\section{Materials and Method}

\subsection{Ethical consideration}

This study follows the guidelines in REporting of studies Conducted using Observational Routinely-collected health Data (RECORD) [3]. The consent of the anonymous participants of the survey was sought prior to participation. The NDHS stores information captured with a variable named CASEID rather than the respondents name; this practice makes each participant anonymous and keeps personal information of the respondents private. Additionally, Demographic Health Survey (DHS) obtained ethical approval from ORC Macro Institutional Review Board.

\subsection{Study area}

This paper is focused on Nigeria. Nigeria which is the most populous country in Africa is divided into 36 states and a Federal Capital Territory (FCT), grouped into six geopolitical zones; North Central, North-East, North-West, South-East, South-South, and South-West.

\subsection{Data source and sampling}

This study utilized data obtained from the Nigeria Demographic and Health Survey (NDHS) for 2003, 2008, 2013 and 2018 for its analysis. The surveys which were implemented by the National Population Commission (NPC) in collaboration with the National Malaria Elimination Programme (NMEP) of the Federal Ministry of Health, 
Nigeria, is nationally representative and collects demographic and health related information for women between the ages of 15 - 49 (reproductive age) through face to face interviews. It employed a probabilistic, stratified multistage sampling technique to select the respondents. A three stage sampling that begins with the selection of Local Government Areas (LGAs) is followed by the selection of Enumeration Areas (EA) which are the Primary Sampling Units (PSU) also referred to as clusters. The systematic selection of households within the selected EAs is the last stage of the sampling. The number of selected households per EA is variable but ranges from 30 to 40 households/women per rural cluster and from 25 to 30 households/women per urban cluster.

Amongst others, the survey collects birth history and other information on all births to each of the interviewed women; therefore, the "child recode data" was used in this study because it contained all follow-up information on all children born to the interviewed women within the five years period preceding each survey year.

\subsection{Data analysis}

In the five years preceding the 2003 NDHS, 6029 children were given birth to from among the 7620 eligible female respondents. In the subsequent NDHS for 2008, 2013 and 2018, 28647, 31482 and $\mathbf{3 3 9 2 4}$ children were given birth from among the 33385, 38948 and 41,821 eligible female respondents respectively. All analysis in this study was based on the survivorship of the $\mathbf{1 0 0 0 8 2}$ children within the first year of their lives.

\subsection{Variables}

Outcome variable: The outcome variable for this study is infant mortality. Question on whether the child was alive or dead, with the responses $1=$ yes (Dead) or $0=$ no (Alive) represent the dependent variable in the dataset.

Table 1: Definition of the outcome variables.

\begin{tabular}{|c|c|c|}
\hline $\begin{array}{c}\text { Dependent variable } \\
\text { (outcome variable) }\end{array}$ & $\begin{array}{c}\text { Answer } \\
\text { category }\end{array}$ & Code \\
\hline \multirow{2}{*}{ Infant mortality } & No & 0 \\
\cline { 2 - 3 } & Yes & 1 \\
\hline
\end{tabular}

The Explanatory variables: The explanatory (independent) variables included in this study are: Mother's Age $=$ MoA, Mother's Region $=$ Reg, Place of residence $=$ PoR, Mother's Education $=$ MoE, Source of Drinking Water $=$ SoDw, Toilet Type $=$ ToT, Mother's Religion $=$ MoR, Cooking Fuel $=\mathrm{CoF}$, Mode of Delivery $=\mathrm{MoD}$, Breast 
Feeding $=\mathrm{BrF}$, Place of Delivery $=\mathrm{PoD}$, Size of Child at Birth $=\mathrm{ScB}$, Number of Antenatal Visits $=\mathrm{NaV}$ and Gender $=$ Gen .

Table 2: Definition of the explanatory variables.

\begin{tabular}{|c|c|c|}
\hline $\mathbf{S} / \mathbf{N}$ & Independent variable & Coding \\
\hline 1 & Mother's Age $=$ MoA & $\begin{array}{l}(15-19)=0,(20-29)=1,(30-39)=2,(40- \\
49)=3\end{array}$ \\
\hline 2 & Mother's Region $=$ Reg & $\begin{array}{l}\text { North central=1, North East }=2 \text {, North } \\
\text { West }=3 \text {, South East }=4 \text {, South South }=5 \text {, } \\
\text { South West }=6\end{array}$ \\
\hline 3 & Place of residence $=$ PoR & Urban $=1$, Rural $=2$ \\
\hline 4 & Mother's Education $=\mathrm{MoE}$ & $\begin{array}{l}\text { No Education=0, Primary=1, Secondary=2, } \\
\text { Higher }=3\end{array}$ \\
\hline 5 & Source of Drinking Water $=\mathrm{SoDw}$ & $\begin{array}{l}\text { improved source }=1 \text {, Non improved source } \\
=2\end{array}$ \\
\hline 6 & Toilet Type $=$ ToT & $\begin{array}{l}\text { Improved sanitation }=1, \\
\text { non-improved sanitation }=2\end{array}$ \\
\hline 7 & Mother's Religion $=\mathrm{MoR}$ & Christian $=1$, Islam $=2$, Traditionalist $=3$ \\
\hline 8 & Cooking Fuel $=\mathrm{CoF}$ & $\begin{array}{l}\text { Kerosene/Electricity/Gas }=1 \text {, } \\
\text { Wood/charcoal/coal }=2\end{array}$ \\
\hline 9 & Mode of Delivery $=$ MoD & Caesarean Section $=1$, Normal Delivery $=2$ \\
\hline 10 & Breast Feeding $=\mathrm{BrF}$ & Not Breast Fed $=0$, Breast Fed $=1$ \\
\hline 11 & Place of Delivery $=$ PoD & Home $=0$, Hospital $=1$, Others $=3$ \\
\hline 12 & Size of Child at Birth $=\mathrm{ScB}$ & Large $=1$, Average $=2$, Small $=3$ \\
\hline 13 & Number of Antenatal Visits $=\mathrm{NaV}$ & None $=0$, Below $5=1$, Above $5=2$ \\
\hline 14 & Gender $=$ Gen & Male $=1$, Female $=2$ \\
\hline
\end{tabular}

Using the child recode data that contains all follow up information on the full birth history of the children born to the eligible interviewed women and the age at death for those whose child/children had died prior to each of the surveys, we computed the conditional life-table age distribution of infant deaths by assigning death and exposure time across each calendar year on a monthly basis using life table techniques embedded in SPSS software version 22 and adjusted our age mortality profiles to match all deaths that occurred from 0 to 11 months. 


\section{Justification for the use of Binary Logistic Regression}

Logistic regression makes use of one or more predictor variables that may be either continuous or categorical data. Unlike ordinary linear regression, however, logistic regression is used for predicting binary outcomes of the dependent variable (treating the dependent variable as the outcome of a Bernoulli trial) rather than a continuous outcome. The binary logistic regression was therefore used in this study in order to examine and predict the likelihood or probability of a child dying at infancy in Nigeria. The regression model enabled the estimation of risk of death relative to the various determinants of interest. In the model, the outcome variable was dichotomized to take the value of " 1 " if the event occurs (i.e., death of a child), and " 0 " if the event does not occur (i.e., child survives).

Other forms of regression models cannot be used for such variables because the predicted value needs to be constrained between 0 and 1 , which is not possible in other forms of regression. It also violates the assumption that the variable is normally (single peak) distributed, since a $(1,0)$ variable by definition has a binomial distribution (double peak). Logistic regression model is used to solve this problem by determining the "odds ratio" or simply 'odds' of an event occurring (i.e., taking a value of 1) against its nonoccurrence (i.e., taking a value of 0 ).

\subsection{Binomial distribution and logistic regression model}

Let $\pi$ be the probability of success (i.e. child died as an infant) for a Bernoulli trial having two possible outcomes (success and failure) and allow $Y$ symbolize the number of successes from the $n$ trials ( $n$ is the total number of children born to the women who participated in the survey). Then $Y$ is binomially distributed with index $n$ and parameter $\pi$ and this is indicated by $Y \sim B(n, \pi)$.

The distribution of $y$ for the random variable $Y$ can be expressed as:

$$
P(y)=\left(\begin{array}{l}
n \\
y
\end{array}\right) \pi^{y}(1-\pi)^{n-y} \quad y=0,1,2, \ldots, n
$$

$Y$ has the expectation $E(Y)=\mu=n \pi$ and standard deviation $\sigma=\sqrt{n \pi(1-\pi)}$.

Now, consider the general logistic regression model with multiple independent variables. Let the $k$ predictors for a binary response $Y$ be represented by $\left(X_{1}, X_{2}, X_{3}, \ldots, X_{k}\right)$, let $\pi(x)$ represent the probability that $Y=1$ for success with probability $\pi(x)=P\left(Y=1 / X_{1}, X_{2}, X_{3}, \ldots, X_{k}\right)$ and $1-\pi(x)$ represent the probability 
that $Y=0$ for failure with probability $1-\pi(x)=P\left(Y=0 / X_{1}, X_{2}, X_{3}, \ldots, X_{k}\right)$, then

$$
\begin{gathered}
\operatorname{logit}(\pi(x))=\log \frac{P\left(Y=1 / X_{1}, X_{2}, X_{3}, \ldots, X_{k}\right)}{P\left(Y=0 / X_{1}, X_{2}, X_{3}, \ldots, X_{k}\right)} \\
\log \left(\frac{\pi(x)}{1-\pi(x)}\right)=\beta_{0}+\beta_{1} x_{1}+\beta_{2} x_{2}+\cdots+\beta_{n} x_{k}+\mu \\
\log \left(\frac{\pi(x)}{1-\pi(x)}\right)=\beta_{0}+\sum_{j=1}^{k} \beta_{j} x_{j}+\mu
\end{gathered}
$$

which gives

$$
\pi(x)=P\left(Y=1 / X_{1}, X_{2}, X_{3}, \ldots, X_{k}\right)=\frac{e^{\beta_{0}+\sum_{j=1}^{k} \beta_{j} x_{j}+\mu}}{1+e^{\beta_{0}+\sum_{j=1}^{k} \beta_{j} x_{j}+\mu}} .
$$

The logit of the logistic regression model to test the significant effect of the independent variables on the outcome variable (infant mortality) for this study is given as

$$
\begin{aligned}
\lambda=\beta_{0}+\beta_{1} \mathrm{MoA}+\beta_{2} \mathrm{Reg}+\beta_{3} \mathrm{PoR},+\beta_{4} \mathrm{MoE}+\beta_{5} \mathrm{SoDw}+\beta_{6} \mathrm{ToT}+\beta_{7} \mathrm{MoR}+ \\
+\beta_{8} \mathrm{CoF}+\beta_{9} \mathrm{MoD}+\beta_{10} \mathrm{BrF}+\beta_{11} \mathrm{PoD}+\beta_{12} \mathrm{ScB}+\beta_{13} \mathrm{NaV}+\beta_{14} \mathrm{Gen}+\mu
\end{aligned}
$$

and the logistic regression model is given as

$$
\begin{aligned}
& \exp \left(\beta_{0}+\beta_{1} M o A+\beta_{2} \operatorname{Reg}+\beta_{3} P o R+\beta_{4} M o E+\beta_{5} \operatorname{SoDw}+\beta_{6} T o T+\beta_{7} M o R+\beta_{8} \mathrm{CoF}+\right. \\
& Y_{\text {inf }}=\frac{\left.\beta_{9} M o D+\beta_{10} B r F+\beta_{11} P o D+\beta_{12} S c B+\beta_{13} N a V+\beta_{14} G e n+\mu\right)}{1+\exp \left(\beta_{0}+\beta_{1} M o A+\beta_{2} \operatorname{Reg}+\beta_{3} P o R+\beta_{4} M o E+\beta_{5} S o D w+\beta_{6} T o T+\beta_{7} M o R+\beta_{8} C o F+\right.} \\
& \left.\beta_{9} M o D+\beta_{10} B r F+\beta_{11} P o D+\beta_{12} S c B+\beta_{13} N a V+\beta_{14} G e n+\mu\right)
\end{aligned}
$$

and

$$
y_{\text {inf }}= \begin{cases}1 & \text { child died as an infant } \\ 0 & \text { child is alive. }\end{cases}
$$

$Y$ is the outcome variable and it is referred to as the logistic transformation of probability of infant mortality occurring. $\beta_{0}$ is the intercept representing the probability of occurrence of the infant mortality in the absence of all the underlying factors. $\beta_{1}, \ldots, \beta_{14}$ are the odds ratios of infant mortality occurring. The " $\mu$ " is the error term.

\subsubsection{Coefficient estimation}

The method of maximum likelihood estimation is employed to approximate the $K+1$ coefficient $\beta=\left(\beta_{0}, \beta_{1}, \ldots, \beta_{k}\right)$ by finding the parameter that maximizes the 
probability of the observed data. The likelihood expression derived from the binomial distribution of the response variable is given by

$$
\begin{gathered}
l(\beta)=\prod_{i=1}^{k} \varphi\left(x_{i}\right)=\prod_{i=1}^{k} \pi\left(x_{i}\right)^{y_{i}}\left[1-\pi\left(x_{i}\right)\right]^{1-y_{i}} \\
l(\beta)=\pi\left(x_{i}\right)^{\sum_{i=1}^{k} y_{i}}\left[1-\pi\left(x_{i}\right)\right]^{k-\sum_{i=1}^{k} y_{i}} \\
l(\beta)=\pi\left(x_{i}\right)^{\sum_{i=1}^{k} y_{i}}\left[1-\pi\left(x_{i}\right)\right]^{k}\left[1-\pi\left(x_{i}\right)\right]^{-\sum_{i=1}^{k} y_{i}} \\
l(\beta)=\left[\frac{\pi\left(x_{i}\right)}{1-\pi\left(x_{i}\right)}\right]^{\sum_{i=1}^{k} y_{i}}\left[1-\pi\left(x_{i}\right)\right]^{k} .
\end{gathered}
$$

But equations 4 and 5 gave the following respectively:

$$
\frac{\pi\left(x_{i}\right)}{1-\pi\left(x_{i}\right)}=e^{\beta_{0}+\sum_{j=1}^{k} \beta_{j} x_{j}} \text { and } \pi\left(x_{i}\right)=\frac{e^{\beta_{0}+\sum_{j=1}^{k} \beta_{j} x_{j}}}{1+e^{\beta_{0}+\sum_{j=1}^{k} \beta_{j} x_{j}}} .
$$

Thus,

$$
\begin{gathered}
l(\beta)=\left(e^{\beta_{0}+\sum_{j=1}^{k} \beta_{j} x_{j}}\right)^{\sum_{i=1}^{k} y_{i}}\left(1-\frac{e^{\beta_{0}+\sum_{j=1}^{k} \beta_{j} x_{j}}}{1+e^{\beta_{0}+\sum_{j=1}^{k} \beta_{j} x_{j}}}\right)^{k} \\
l(\beta)=\left(e^{\beta_{0} \sum_{i=1}^{k} y_{i}+\sum_{i=1}^{k} y_{i} \sum_{j=1}^{k} \beta_{j} x_{j}}\right)\left(\frac{1+e^{\beta_{0}+\sum_{j=1}^{k} \beta_{j} x_{j}}-e^{\beta_{0}+\sum_{j=1}^{k} \beta_{j} x_{j}}}{1+e^{\beta_{0}+\sum_{j=1}^{k} \beta_{j} x_{j}}}\right)^{k} \\
l(\beta)=\left(e^{\beta_{0} \sum_{i=1}^{k} y_{i}+\sum_{i=1}^{k} y_{i} \sum_{j=1}^{k} \beta_{j} x_{j}}\right)\left(\frac{1}{1+e^{\beta_{0}+\sum_{j=1}^{k} \beta_{j} x_{j}}}\right)^{k} \\
l(\beta)=\left(e^{\beta_{0} \sum_{i=1}^{k} y_{i}+\sum_{i=1}^{k} y_{i} \sum_{j=1}^{k} \beta_{j} x_{j}}\right)\left(1+e^{\beta_{0}+\sum_{j=1}^{k} \beta_{j} x_{j}}\right)^{-k}
\end{gathered}
$$

where

$$
\beta=\left(\beta_{0}, \beta_{1}, \ldots, \beta_{k}\right) \text { and } l(\beta) \text { is the likelihood function of } \beta \text {. }
$$

The Maximum likelihood Estimates (MLE's) denoted by $\tilde{\beta}_{0}, \tilde{\beta}_{1}, \tilde{\beta}_{2}, \ldots, \tilde{\beta}_{k}$ can be found by computing $\beta$ which maximizes $l(\beta)$. This is achieved by taking the logarithm of equation (10) which is represented by $L(\beta)$ and it is called the log likelihood function:

$$
L(\beta)=\log (l(\beta))=\left(e^{\beta_{0} \sum_{i=1}^{k} y_{i}+\sum_{i=1}^{k} y_{i} \sum_{j=1}^{k} \beta_{j} x_{j}}\right)\left(1+e^{\beta_{0}+\sum_{j=1}^{k} \beta_{j} x_{j}}\right)^{-k}
$$




$$
L(\beta)=\log (l(\beta))=\left(\beta_{0} \sum_{i=1}^{k} y_{i}+\sum_{i=1}^{k} y_{i} \sum_{j=1}^{k} \beta_{j} x_{j}\right)-k \log \left(1+e^{\beta_{0}+\sum_{j=1}^{k} \beta_{j} x_{j}}\right) .
$$

Calculating the maximum likelihood estimates requires us to find the first derivative of the $\log$ likelihood function $L(\beta)$. This is done by differentiating equation (10) with respect to $\beta_{0}$, leading to:

$$
\begin{gathered}
\frac{\partial L(\beta)}{\partial \beta_{0}}=\sum_{i=1}^{k} y_{i}-k \frac{e^{\beta_{0}+\sum_{j=1}^{k} \beta_{j} x_{j}}}{1+e^{\beta_{0}+\sum_{j=1}^{k} \beta_{j} x_{j}}} \\
\frac{\partial L(\beta)}{\partial \beta_{0}}=\sum_{i=1}^{k} y_{i}-k \pi\left(x_{i}\right) \\
\frac{\partial L(\beta)}{\partial \beta_{0}}=\sum_{i=1}^{k}\left[y_{i}-k \pi\left(x_{i}\right)\right] .
\end{gathered}
$$

Differentiating (10) with respect to $\beta_{j}$, we have

$$
\begin{gathered}
\frac{\partial L(\beta)}{\partial \beta_{j}}=\sum_{i=1}^{k} y_{i} \sum_{j=1}^{k} x_{j}-k \sum_{j=1}^{k} x_{j} \frac{e^{\beta_{0}+\sum_{j=1}^{k} \beta_{j} x_{j}}}{1+e^{\beta_{0}+\sum_{j=1}^{k} \beta_{j} x_{j}}} \\
\frac{\partial L(\beta)}{\partial \beta_{j}}=\sum_{i=1}^{k} y_{i} \sum_{j=1}^{k} x_{j}-k \sum_{j=1}^{k} x_{j} \pi\left(x_{i}\right) \\
\frac{\partial L(\beta)}{\partial \beta_{j}}=\sum_{i=1}^{k} x_{i k}\left[y_{i}-\pi\left(x_{i}\right)\right] .
\end{gathered}
$$

The required estimates $\tilde{\beta}_{0}$ and $\tilde{\beta}_{j}$ estimating $\beta_{0}$ and $\beta_{j}$ are calculated by equating (12) and (13) to zero and solving for each $\tilde{\beta}_{j}$.

\subsubsection{Model assessment using likelihood ratio test}

A logistic model is a better fit to a given data if it establishes an improvement over the null model (intercept only model with no explanatory variables). The assessment of the significance of regression parameters employed the likelihood ratio test. This test uses $\chi^{2}$ statistics under the null hypothesis:

$$
H_{0}=\beta_{1}=\beta_{2}=\cdots=\beta_{k}=0
$$


and $\chi^{2}$ statistic is computed as

$$
\chi^{2}=(-2 \text { LL of null model })-(-2 \text { LL of model with variables }) .
$$

Therefore

$$
G=\chi^{2}=-2 \log \left(\frac{\text { likelihood of null model }}{\text { likelihood of model with variables }}\right) .
$$

$G$ is a chi-square distribution having $k$ degrees of freedom where $k$ represent the number of covariates in the logistic regression model given in (7). When the $p$-value of the overall model fit statistic is less than 0.05 , we reject $H_{0}$ at $\alpha=0.05$, and we conclude that there is at least one predictor variables whose coefficient is not zero and as a result adds to the prediction of the outcome.

\subsubsection{Statistical analysis}

The analysis of the study based on the selected infant mortality variables was carried out in stages. First, the frequency distributions of the independent variables according to the background characteristics of interest were analyzed for each of the 2003, 2008, 2013 and 2018 survey years using SPSS and the results displayed in Table 3. The Chi-Square test of association was then employed to determine the significant bivariate correlation between infant mortality and the risk factors of the selected independent variables. Estimates of infant mortality rates for the five years preceding each of the 2003, 2008, 2013 and 2018 surveys were subsequently calculated and the results presented in Table 4. The Average Rate of Reduction for infant mortality rate in Nigeria was calculated and the results presented in Table 5. Finally, the significant determinants of infant mortality in Nigeria using logistic regression model was determined. The logistic regression test was conducted at 5\% level of significance and the results (odds ratio and statistical significance) displayed in Table 6.

\subsubsection{Computation of the annual rate of reduction (ARR)}

Let $I M R_{X}$ denote the Infant Mortality Rate for 2003 (X is the start year).

Let $I M R_{Y}$ denote the Infant Mortality Rate for 2018 (Y is the end year).

Then, the Annual Rate of Reduction (ARR) for infant mortality is given as

$$
A R R_{I M}=\frac{100\left(I M R_{X}-I M R_{Y}\right)}{I M R_{X}(Y-X)} .
$$




\section{Results and Discussion}

Table 3: Frequency distribution of the independent variables.

\begin{tabular}{|c|c|c|c|c|}
\hline & 2003 & 2008 & 2013 & 2018 \\
\hline Variables & Frequency (\%) & Frequency $(\%)$ & Frequency (\%) & Frequency $(\%)$ \\
\hline \multicolumn{5}{|l|}{ Mother's Age } \\
\hline $15-19$ & $385 \quad(6.4 \%)$ & $1584(5.5 \%)$ & $1531(4.9 \%)$ & $1434(4.2 \%)$ \\
\hline $20-29$ & $3033(50.3 \%)$ & $13787(48.1 \%)$ & $14845(47.2 \%)$ & $16096(47.4 \%)$ \\
\hline $30-39$ & 2025 (33.6\%) & $10242(35.8 \%)$ & 11859 (37.7\%) & $13094(38.6 \%)$ \\
\hline $40-49$ & $586 \quad(9.7 \%)$ & $3034(10.6 \%)$ & $3247(10.3 \%)$ & $3300(9.7 \%)$ \\
\hline Total & $6029(100 \%)$ & $28647(100 \%)$ & $31482(100 \%)$ & $33924(100 \%)$ \\
\hline \multicolumn{5}{|l|}{ Mother's Region } \\
\hline North Central & $1015(16.8 \%)$ & $5046(17.6 \%)$ & $4614(14.7 \%)$ & $5875(17.3 \%)$ \\
\hline North East & $1487(24.7 \%)$ & $6559(22.9 \%)$ & $6517(20.7 \%)$ & $7211(21.3 \%)$ \\
\hline North West & $1821(30.2 \%)$ & 7947 (27.7\%) & $9906(31.5 \%)$ & 10305 (30.4\%) \\
\hline South East & $524(8.7 \%)$ & $2450(8.6 \%)$ & $2816(8.9 \%)$ & $3798(11.2 \%)$ \\
\hline South South & $560(9.3 \%)$ & 3327 (11.6\%) & $3747(11.9)$ & $3202(9.4 \%)$ \\
\hline South West & $622(10.3 \%)$ & $3318(11.6 \%)$ & $3882(12.3 \%)$ & $3533(10.4 \%)$ \\
\hline Total & $6029(100 \%)$ & $28647(100 \%)$ & $31482(100 \%)$ & $33924(100 \%)$ \\
\hline \multicolumn{5}{|l|}{ Place of Residence } \\
\hline Rural & $3911(64.9 \%)$ & $21034(73.4 \%)$ & $21131(67.1 \%)$ & $22225(65.5 \%)$ \\
\hline Urban & $2118(35.1 \%)$ & $7613(26.6 \%)$ & $10351(32.9 \%)$ & $11699(34.5 \%)$ \\
\hline Total & $6029(100 \%)$ & $28647(100 \%)$ & $31482(100 \%)$ & $33924(100 \%)$ \\
\hline \multicolumn{5}{|l|}{ Mother's Education } \\
\hline No Education & 3033 (50.3\%) & $14418(50.3 \%)$ & $14762(46.9 \%)$ & $15391(45.4 \%)$ \\
\hline Primary & $1473(24.4 \%)$ & $6552(22.9 \%)$ & $6432(20.4 \%)$ & $5274(15.5 \%)$ \\
\hline Secondary & $1308(21.7 \%)$ & $6338(22.1 \%)$ & $8365(26.6 \%)$ & $10623(31.3 \%)$ \\
\hline Higher & $215(3.6 \%)$ & $1339(4.7 \%)$ & $1923(6.1 \%)$ & $2636(7.8 \%)$ \\
\hline Total & $6029(100 \%)$ & $28647(100 \%)$ & $31482(100 \%)$ & $33924(100 \%)$ \\
\hline \multicolumn{5}{|l|}{ Source of Drinking Water } \\
\hline Unimproved Source & $4421(73.3 \%)$ & $14703(51.3 \%)$ & $12519(39.8 \%)$ & $21382(63.0 \%)$ \\
\hline Improved Source & $1608(26.7 \%)$ & $13506(47.1 \%)$ & $18308(58.2 \%)$ & $12542(37.0 \%)$ \\
\hline Total & $6029(100 \%)$ & $28209(98.5 \%)$ & $30827(97.9 \%)$ & $33924(100 \%)$ \\
\hline \multicolumn{5}{|l|}{ Toilet Type } \\
\hline Unimproved Toilet Sanitation & $5245(87.0 \%)$ & $25357(88.5 \%)$ & $26704(84.8 \%)$ & $27374(80.7 \%)$ \\
\hline Improved Toilet Sanitation & $590(9.8 \%)$ & $2955(10.3 \%)$ & $4474(14.2 \%)$ & $6550(19.3 \%)$ \\
\hline Total & $5835(96.8 \%)$ & $28312(98.8 \%)$ & $31178(99.0 \%)$ & $33924(100 \%)$ \\
\hline \multicolumn{5}{|l|}{ Mother's Religion } \\
\hline Christian & $2307(38.3 \%)$ & $11738(41.0 \%)$ & $12654(40.2 \%)$ & $13239(39.0 \%)$ \\
\hline Islam & $3598(59.7 \%)$ & $16152(56.4 \%)$ & $18354(58.3 \%)$ & $20412(60.2 \%)$ \\
\hline Traditionalist & $119(2.0 \%)$ & $757(2.6 \%)$ & $474(1.5 \%)$ & $273(0.8 \%)$ \\
\hline Total & $6024(99.9 \%)$ & $28647(100 \%)$ & $31482(100 \%)$ & $33924(100 \%)$ \\
\hline \multicolumn{5}{|l|}{ Cooking Fuel } \\
\hline Wood/Charcoal/Coal & $4863(80.7 \%)$ & $24550(85.7 \%)$ & $25824(82.0 \%)$ & $28763(84.8 \%)$ \\
\hline Kerosene/Electricity/Gas & $1065(17.7 \%)$ & $3838(13.4 \%)$ & $5359(17.0 \%)$ & $5161(15.2 \%)$ \\
\hline Total & $5928(98.3 \%)$ & $28388(99.1 \%)$ & $31183(99.1 \%)$ & $33924(100 \%)$ \\
\hline Mode of Delivery & & & & \\
\hline
\end{tabular}




\begin{tabular}{|c|c|c|c|c|}
\hline Caesarean Section & $75(1.2 \%)$ & $468(1.6 \%)$ & $697(2.2 \%)$ & $879(2.6 \%)$ \\
\hline Normal Delivery & $3654(60.6 \%)$ & $28164(98.3 \%)$ & $30590(97.2 \%)$ & $32899(97.0)$ \\
\hline Total & $3729(61.9 \%)$ & $28632(99.9 \%)$ & 31287 (99.4\%) & $33778(99.6 \%)$ \\
\hline \multicolumn{5}{|l|}{ Breast Feeding } \\
\hline Not Breast Fed & 3488 (57.9\%) & $12437(43.4 \%)$ & $14290(45.4 \%)$ & $16068(47.4 \%)$ \\
\hline Breast Fed & $2541(42.1)$ & $16210(56.6 \%)$ & $17192(54.6 \%)$ & $17856(52.6 \%)$ \\
\hline Total & $6029(100 \%)$ & $28647(100 \%)$ & $31482(100 \%)$ & 33924 (100\%) \\
\hline \multicolumn{5}{|l|}{ Place of Delivery } \\
\hline Home & $3853(63.9 \%)$ & $18990(66.3 \%)$ & $19619(62.3 \%)$ & 19949 (58.8\%) \\
\hline Hospital & $2094(34.7 \%)$ & $8958(31.3 \%)$ & $11512(36.6 \%)$ & $13488(39.8 \%)$ \\
\hline Others & $25(0.4 \%)$ & $699(2.4 \%)$ & $351(1.1 \%)$ & $487(1.4 \%)$ \\
\hline Total & $5972(99.1)$ & $28647(100 \%)$ & $31482(100 \%)$ & $33924(100 \%)$ \\
\hline \multicolumn{5}{|l|}{ Size of Child } \\
\hline Large & $2497(41.4 \%)$ & $13012(45.4 \%)$ & $13589(43.2 \%)$ & $11275(33.2 \%)$ \\
\hline Average & $2557(42.4 \%)$ & $10732(37.5 \%)$ & $12689(40.3 \%)$ & $17551(51.7 \%)$ \\
\hline Small & $975(16.2 \%)$ & $4903(17.1 \%)$ & $5204(16.5 \%)$ & $4572(13.5 \%)$ \\
\hline Total & $6029(100 \%)$ & $28647(100 \%)$ & $31482(100 \%)$ & $33398(100 \%)$ \\
\hline \multicolumn{5}{|l|}{ Antenatal Visits } \\
\hline None & $1349(22.4 \%)$ & $7013(24.5 \%)$ & $7082(22.5 \%)$ & $17824(52.5 \%)$ \\
\hline Below 5 & $781(13.0 \%)$ & $3180(11.1 \%)$ & $4122(13.1 \%)$ & $8853(26.1 \%)$ \\
\hline 5 and Above & $1631(27.1 \%)$ & $6471(22.6 \%)$ & $8868(28.2 \%)$ & $7247(21.4 \%)$ \\
\hline Total & $3761(62.4 \%)$ & $16664(58.2 \%)$ & $20072(63.8 \%)$ & $33924(100 \%)$ \\
\hline \multicolumn{5}{|l|}{ Gender } \\
\hline Male & $3062(50.8 \%)$ & $14604(51.0 \%)$ & $15965(50.7 \%)$ & $17257(50.9 \%)$ \\
\hline Female & $2967(49.2 \%)$ & $14043(49.0 \%)$ & $15517(49.3 \%)$ & $16667(49.1 \%)$ \\
\hline Total & $6029(100 \%)$ & $28647(100 \%)$ & $31482(100 \%)$ & 33924 \\
\hline \multicolumn{5}{|l|}{ Infant Mortality } \\
\hline Infant deaths & $694(11.5 \%)$ & $2349(8.2 \%)$ & $2513(8.0 \%)$ & $2705(8.0 \%)$ \\
\hline Total number of live births & $6029(100 \%)$ & $28,647(100 \%)$ & $31482(100 \%)$ & $33924(100 \%)$ \\
\hline Infant mortality rate & 115 & 82 & 80 & 80 \\
\hline
\end{tabular}

Table 3 displays the frequency distribution of the selected infant mortality variables used in this study. The total number of children born to the interviewed mothers for each of the five years preceding the 2003, 2008, 2013 and 2018 surveys are 6029, 28647, 31482,33924 respectively. The total for some of the variables differs and are less than $100 \%$ due to missing values and no responses. The results in Table 3 indicates that the number of children born to the respondents were consistently higher for women between the ages of 20 and 29 with 50.3\%, 48.1\%, 47.2\% and 47.4\% in 2003, 2008, 2013 and 2018 respectively. The population percentage of participating children for each of the survey years was higher for children born in the Northern region than for those given birth to in the Southern region with the highest number of children given birth to in the North West and the lowest number of children born in the South East with the 2018 survey year being the only exception as the South South region recorded the lowest 
percentage of children born to the respondents. Also, a larger percentage of the respondents were rural dweller with a percentage of over $60 \%$ in each of the survey years residing in rural settlements. Table 3 also shows that over $45 \%$ of the children born to the interviewed mothers in each of the survey years had no formal education with only $3.6 \%$, $4.7 \%, 6.1 \%$, and $7.8 \%$ of the children born to the respondents in 2003, 2008, 2013 and 2018 having a tertiary education.

Since majority of the respondents were rural dwellers with possibly little or no access to good water, means of obtaining clean cooking fuel and modern toilet facilities, it is therefore of no surprise that a greater number of the children born to the respondents lived in households using unclean cooking fuel such as wood and charcoal with unimproved source of water and unimproved toilet sanitation for each of the survey years. A higher number of the babies were given birth to the interviewed mothers at home representing $63.9 \%, 66.3 \%, 62.3 \%$ and 58.8\% in 2003, 2008, 2013 and 2018 respectively relative to the number of children born in the hospital. Also, only $13 \%, 11.1 \%, 13.1 \%$ and $26.1 \%$ of the children of the respondents given birth to in the hospital received antenatal care less than five times before their delivery.

On breast feeding, $42.1 \%, 56.6 \%, 54.6 \%$ and $52.6 \%$ of the babies born in each of the five years preceding the 2003, 2008, 2013 and 2018 surveys respectively were breast fed by their mothers. The percentage of boys given birth to in each of the survey years were consistently higher slightly with just over $50 \%$ for each of the survey yeas relative to the percentage of female babies. Overall, the total number of estimated infants' death for the five years preceding each survey is 694, 2349, 2513 and 2705 representing 11.5\%, 8.2\%, $8 \%$ and $8 \%$ respectively. This also signifies that infant mortality rates have stagnated in the last decade.

Table 4: Estimates of Infant Mortality rates per 1,000 live births for the five years preceding each survey.

\begin{tabular}{|l|c|c|c|c|}
\hline Variables & $\mathbf{2 0 0 3}$ & $\mathbf{2 0 0 8}$ & $\mathbf{2 0 1 3}$ & $\mathbf{2 0 1 8}$ \\
\hline Mother's Age & \multicolumn{4}{|c|}{} \\
\hline $15-19$ & 135 & 101 & 111 & 96 \\
\hline $20-29$ & 111 & 79 & 75 & 78 \\
\hline $30-39$ & 110 & 79 & 83 & 77 \\
\hline $40-49$ & 138 & 93 & 95 & 92 \\
\hline Mother's Region & 101 & 73 & 63 & 71 \\
\hline North Central & 139 & 89 & 86 & 86 \\
\hline North East & \multicolumn{5}{|l}{} \\
\hline
\end{tabular}




\begin{tabular}{|c|c|c|c|c|}
\hline North West & 125 & 92 & 98 & 105 \\
\hline South East & 97 & 88 & 88 & 62 \\
\hline South South & 114 & 82 & 63 & 52 \\
\hline South West & 69 & 53 & 61 & 51 \\
\hline \multicolumn{5}{|l|}{ Place of Residence } \\
\hline Rural & 132 & 89 & 90 & 88 \\
\hline Urban & 85 & 63 & 60 & 64 \\
\hline \multicolumn{5}{|l|}{ Mother's Education } \\
\hline No Education & 138 & 91 & 94 & 97 \\
\hline Primary & 117 & 83 & 83 & 81 \\
\hline Secondary & 67 & 70 & 61 & 62 \\
\hline Higher & 70 & 38 & 43 & 50 \\
\hline \multicolumn{5}{|l|}{ Source of Drinking Water } \\
\hline Unimproved Source & 120 & 92 & 88 & 82 \\
\hline Improved Source & 101 & 71 & 74 & 75 \\
\hline \multicolumn{5}{|l|}{ Toilet Type } \\
\hline Unimproved Toilet Sanitation & 120 & 85 & 84 & 85 \\
\hline Improved Toilet Sanitation & 53 & 54 & 53 & 58 \\
\hline \multicolumn{5}{|l|}{ Mother's Religion } \\
\hline Christian & 97 & 77 & 70 & 62 \\
\hline Islam & 123 & 85 & 87 & 92 \\
\hline Traditionalist & 135 & 100 & 80 & 40 \\
\hline \multicolumn{5}{|l|}{ Cooking Fuel } \\
\hline Wood/Charcoal/Coal & 124 & 86 & 85 & 93 \\
\hline Kerosene /Electricity/Gas & 75 & 55 & 53 & 49 \\
\hline \multicolumn{5}{|l|}{ Mode of Delivery } \\
\hline Caesarean Section & 93 & 115 & 104 & 92 \\
\hline Normal Delivery & 76 & 81 & 79 & 80 \\
\hline \multicolumn{5}{|l|}{ Breast Feeding } \\
\hline Not Breast Fed & 76 & 122 & 118 & 112 \\
\hline Breast Fed & 69 & 51 & 48 & 51 \\
\hline \multicolumn{5}{|l|}{ Place of Delivery } \\
\hline Home & 128 & 85 & 86 & 89 \\
\hline Hospital & 80 & 68 & 62 & 67 \\
\hline Others & 80 & 207 & 327 & 76 \\
\hline \multicolumn{5}{|l|}{ Size of Child } \\
\hline Large & 96 & 68 & 63 & 72 \\
\hline Average & 108 & 78 & 77 & 73 \\
\hline Small & 183 & 126 & 130 & 117 \\
\hline \multicolumn{5}{|l|}{ Antenatal Visits } \\
\hline None & 102 & 67 & 66 & 106 \\
\hline Below 5 & 68 & 52 & 54 & 52 \\
\hline 5 and Above & 55 & 46 & 45 & 48 \\
\hline
\end{tabular}




\begin{tabular}{|l|c|c|c|c|}
\hline Gender & \multicolumn{4}{|l|}{} \\
\hline Male & 121 & 89 & 86 & 85 \\
\hline Female & 108 & 74 & 73 & 75 \\
\hline Total & 115 & 82 & 80 & 80 \\
\hline
\end{tabular}

Table 4 is a display of the estimates of infant mortality rates in Nigeria for the five year period preceding each of the 2003, 2008, 2013 and 2018 NDHS based on the selected infant mortality variables. From Table 4, the overall infant mortality rates can be seen to have reduced in subsequent years from 115/1,000 live births in 2003 through $82 / 1,000$ live births in 2008 to $80 / 1,000$ live births in 2013 before seemingly remaining stagnant at 80/1,000 live births for the five year period preceding 2018 survey. The estimated infant mortality rates for teenage mothers reduced from 135/1,000 live births in 2003 to 96/1,000 live births in 2018 with mothers between the ages of $20-39$ experiencing considerably lower infant mortality rates from 2003 through 2018. Mothers who resided in urban centers experienced significantly reduced infant mortality rates compared to those who lived in rural settlements with $85 / 1,000$ live births versus 132/1,000 live births in 2003 reducing through the years to 64/1,000 live births and 84/1,000 live births in 2018 respectively. Furthermore, the result in Table 4 suggests that female children in Nigeria experienced less mortality at infancy compared to their male counterpart with consistently lower infant mortality rates from 2003 through 2018. On breast feeding, infant mortality rates (76, 122, 118 and 112)/1,000 live births was higher for children who were not breastfed compared to those who were breastfed $(69,51,48$ and 51)/1,000 live births in 2003, 2008, 2013 and 2018 respectively. The infant mortality estimates for the size of the child at birth shows that babies who were small at birth experienced more mortality $(183,126,130,117)$ per 1,000 live births compared to babies who were large in size $(96,68,63,72)$ per 1,000 live births in 2003, 2008, 2013 and 2018 respectively. Considering the mode of delivery and number of antenatal visits, babies who were given birth to in the hospital experienced significantly lowered infant mortality rates than those who were born at home. Children who were given birth to after their mothers attended antenatal care on five or more occasions also recorded significantly less infant mortality from 2003 through 2018 relative to babies born without any doctor's appointment prior to their delivery. Also, infant mortality rates were significantly higher among children who had water from unimproved sources and used unimproved toilet types for each of the 2003, 2008, 2013 and 2018 survey years. All the infant mortality rate estimates were calculated at $95 \%$ confidence level using Pearson Chi-square $\left(\chi^{2}\right)$ test of association. 
Table 5: Summary of Infant Mortality Rates.

\begin{tabular}{|c|c|c|c|c|}
\hline & 2003 & 2008 & 2013 & 2018 \\
\hline Estimated IMR & 115 & 82 & 80 & 80 \\
\hline ARR & NC & $5.7 \%$ & $0.5 \%$ & $0 \%$ \\
\hline NDHS IMR & 100 & 75 & 69 & 67 \\
\hline ARR & NC & $5.0 \%$ & $1.6 \%$ & $0.6 \%$ \\
\hline
\end{tabular}

$I M R=$ Infant Mortality Rate, ARR= Annual Rate of Reduction, NC=Not Computed

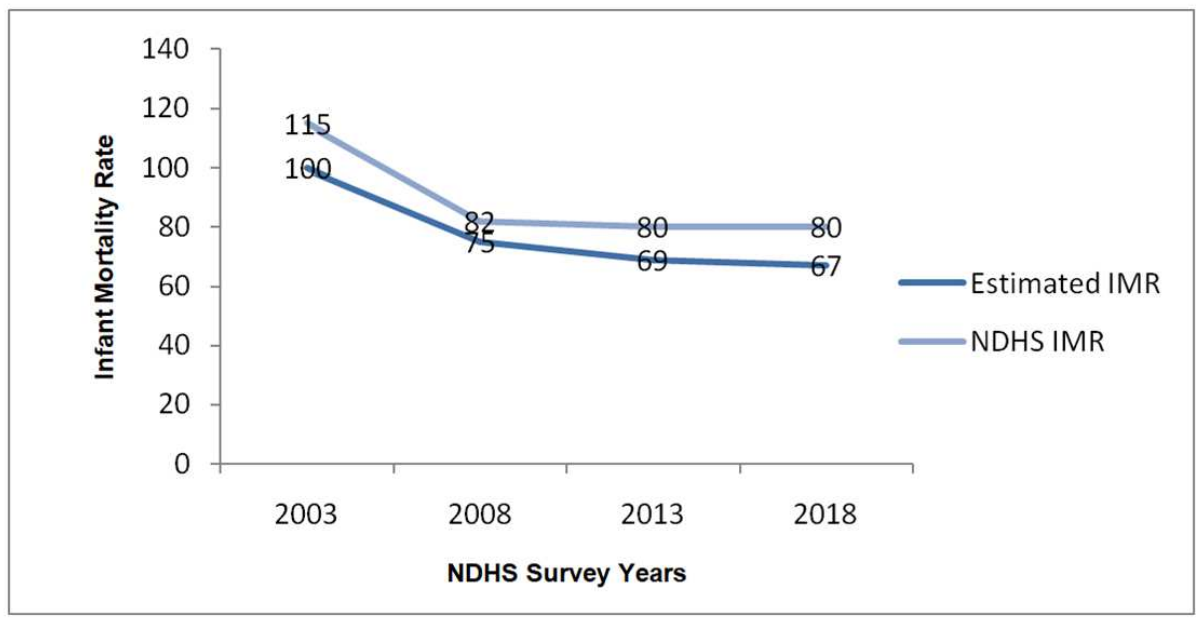

Figure 1: Infant Mortality Trend.

Table 5 presents the levels of infant mortality rate from 2003 to 2018 as well as the periodic Annual Rate of Reduction (ARR). The periodic ARR for 2003 was not computed because this study did not consider estimates of the previous NDHS survey necessary to compute the periodic ARR for 2003. From Table 5, the current estimated infant mortality rate is $80 / 1,000$ live births for the five years preceding the 2018 survey. Compared to estimates of infant mortality rates in 2003 which stands at 115/1,000 live births; there have been a steady decline. However, this reduction in infant mortality which fell short of the target of childhood mortality goals as contained in the Millennium Development Goals (MDG) in 2015, may not be enough (if current ARR for infant mortality remains constant) to attain the target for childhood mortality as contained in the Sustainable Development Goals (SDG) given the percentage of under-five deaths that occurs at infancy. Figure 1 reveals an initial downward trend in infant mortality rate from 2003 to 2008 with an ARR of 5.7\%. This high ARR could not be sustained over the years 
with the rate of reduction in infant mortality shrinking to $0.3 \%$ in 2013 until the ARR hits $0 \%$ for the five years preceding the 2018 survey indicative of a stunted reduction in infant mortality. If mortality rate targets are to be met, the overall infant mortality ARR from 2003 up until 2018 which is about $2.0 \%$ needs to be improved upon. On current levels and trends, a projected infant mortality rate of 52 per 1000 live births by 2030 based on the ARR between 2003 and 2018 resulting to 33\% of deaths in under-five mortality in Nigeria will lead to the country falling short of the SDG for childhood mortality unless suitable interventions already put in place are rigorously pursued.

Table 6: Effects of the determinants of Infant Mortality for the five years preceding 2003-2018.

\begin{tabular}{|c|c|c|c|c|c|c|c|c|}
\hline \multirow{2}{*}{ Variables } & \multicolumn{2}{|c|}{2003} & \multicolumn{2}{|c|}{2008} & \multicolumn{2}{|c|}{2013} & \multicolumn{2}{|c|}{2018} \\
\hline & O.R & Sig. & O.R & Sig. & O.R & Sig. & O.R & Sig. \\
\hline \multicolumn{9}{|l|}{ Mother's Age } \\
\hline $15-19^{\mathrm{RC}}$ & 1.000 & & & & & & & \\
\hline $20-29$ & 0.757 & 0.000 & 0.746 & 0.000 & 0.780 & 0.000 & 0.821 & 0.007 \\
\hline $30-39$ & 0.879 & 0.000 & 0.891 & 0.012 & 0.804 & 0.002 & 0.834 & 0.004 \\
\hline $40-49$ & 0.974 & 0.021 & 0.933 & 0.023 & 0.836 & 0.046 & 1.049 & 0.049 \\
\hline \multicolumn{9}{|l|}{ Mother's Region } \\
\hline North Central ${ }^{\mathbf{R C}}$ & 1.000 & & & & & & & \\
\hline North East & 0.658 & 0.000 & 0.776 & 0.000 & 0.959 & 0.065 & 0.975 & 0.819 \\
\hline North West & 0.689 & 0.000 & 0.820 & 0.027 & 0.898 & 0.024 & 0.815 & 0.044 \\
\hline South East & 0.521 & 0.084 & 0.879 & 0.012 & 0.643 & 0.000 & 0.709 & 0.000 \\
\hline South South & 0.462 & 0.007 & 0.608 & 0.000 & 0.561 & 0.000 & 0.458 & 0.000 \\
\hline South West & 0.576 & 0.027 & 0.810 & 0.002 & 0.631 & 0.000 & 0.577 & 0.000 \\
\hline \multicolumn{9}{|l|}{ Place of Residence } \\
\hline Rural $^{\mathbf{R C}}$ & 1.000 & & & & & & & \\
\hline Urban & 0.609 & 0.000 & 0.694 & 0.000 & 0.643 & 0.000 & 0.703 & 0.000 \\
\hline \multicolumn{9}{|l|}{ Mother's Education } \\
\hline No Education ${ }^{\mathbf{R C}}$ & 1.000 & & & & & & & \\
\hline Primary & 0.897 & 0.000 & 0.523 & 0.000 & 0.690 & 0.002 & 0.807 & 0.028 \\
\hline Secondary & 0.564 & 0.040 & 0.440 & 0.000 & 0.430 & 0.000 & 0.603 & 0.000 \\
\hline Higher & 0.468 & 0.005 & 0.396 & 0.000 & 0.489 & 0.000 & 0.496 & 0.000 \\
\hline \multicolumn{9}{|l|}{ Source of Drinking Water } \\
\hline Unimproved Source ${ }^{\mathbf{R C}}$ & 1.000 & & & & & & & \\
\hline
\end{tabular}




\begin{tabular}{|c|c|c|c|c|c|c|c|c|}
\hline Improved Source & 0.819 & 0.035 & 0.753 & 0.000 & 0.821 & 0.000 & 0.907 & 0.020 \\
\hline \multicolumn{9}{|l|}{ Toilet Type } \\
\hline $\begin{array}{ll}\text { Unimproved } & \text { Toilet } \\
\text { Sanitation RC } & \\
\end{array}$ & 1.000 & & & & & & & \\
\hline $\begin{array}{ll}\text { Improved } & \text { Toilet } \\
\text { Sanitation } & \end{array}$ & 0.405 & 0.000 & 0.612 & 0.000 & 0.601 & 0.000 & 0.657 & 0.000 \\
\hline \multicolumn{9}{|l|}{ Mother's Religion } \\
\hline Christian $^{\mathbf{R C}}$ & 1.000 & & & & & & & \\
\hline Islam & 1.286 & 0.102 & 1.202 & 0.160 & 1.165 & 0.377 & 1.571 & 0.145 \\
\hline Traditionalist & 1.349 & 0.071 & 1.077 & 0.569 & 0.916 & 0.610 & 1.409 & 0.004 \\
\hline \multicolumn{9}{|l|}{ Cooking Fuel } \\
\hline Wood/Charcoal/Coal ${ }^{\text {RC }}$ & 1.000 & & & & & & & \\
\hline Kerosene/Electricity/Gas & 0.575 & 0.000 & 0.625 & 0.000 & 0.606 & 0.000 & 0.553 & 0.000 \\
\hline \multicolumn{9}{|l|}{ Mode of Delivery } \\
\hline Caesarean Section $^{\mathbf{R C}}$ & 1.000 & & & & & & & \\
\hline Normal Delivery & 0.797 & 0.572 & 0.680 & 0.008 & 0.737 & 0.015 & 0.852 & 0.017 \\
\hline \multicolumn{9}{|l|}{ Breast Feeding } \\
\hline Not Breast Fed $^{\mathbf{R C}}$ & 1.000 & & & & & & & \\
\hline Breast Fed & 0.405 & 0.000 & 0.386 & 0.000 & 0.378 & 0.000 & 0.428 & 0.000 \\
\hline \multicolumn{9}{|l|}{ Place of Delivery } \\
\hline Home $^{\mathbf{R C}}$ & 1.000 & & & & & & & \\
\hline Hospital & 0.593 & 0.022 & 0.449 & 0.000 & 0.527 & 0.000 & 0.845 & 0.030 \\
\hline Others & 0.997 & 0.079 & 0.354 & 0.121 & 0.731 & 0.000 & 1.151 & 0.419 \\
\hline \multicolumn{9}{|l|}{ Size of Child } \\
\hline Large $^{\mathbf{R C}}$ & 1.000 & & & & & & & \\
\hline Average & 0.871 & 0.039 & 0.590 & 0.000 & 0.553 & 0.000 & 0.594 & 0.000 \\
\hline Small & 1.474 & 0.000 & 1.296 & 0.000 & 1.305 & 0.021 & 1.141 & 0.014 \\
\hline \multicolumn{9}{|l|}{ Antenatal Visits } \\
\hline None $^{\mathbf{R C}}$ & 1.000 & & & & & & & \\
\hline Below 5 & 0.793 & 0.000 & 0.883 & 0.000 & 0.834 & 0.035 & 0.920 & 0.025 \\
\hline 5 and Above & 0.506 & 0.008 & 0.721 & 0.029 & 0.666 & 0.000 & 0.424 & 0.000 \\
\hline \multicolumn{9}{|l|}{ Gender } \\
\hline Male $^{\mathbf{R C}}$ & 1.000 & & & & & & & \\
\hline Female & 0.875 & 0.098 & 0.817 & 0.000 & 0.832 & 0.000 & 0.805 & 0.871 \\
\hline
\end{tabular}

O.R = Odds Ratio, Sig. = Significance level, $R C=$ Reference Category 
The results of the logistic regression model used to identify the significant determinants of infant mortality for the five years preceding each of the 2003, 2008, 2013 and 2018 NDHS are presented in Table 6. There are two distinct columns for each of the survey years. The first column for each survey year displays the Odds Ratio (OR) which is the exponential of the parameter estimates from the model at $95 \%$ Confidence Interval (CI). The odds ratio defines the chances of occurrence of infant mortality with respect to the reference category for each of the infant mortality variables. The second column gives the associated $P$-value which measures the degree of statistical significance of the odds ratio. From Table 6, the odds of infant mortality for mothers between the ages of $20-29$ $(0.757,0.746,0.780$ and 0.821$)$ was consistently lower for each of the respective survey years than for teenage mothers with $P$-value of 0.000 indicating statistical significance. Based on the geopolitical location of mothers, the chances of infant mortality is reduced by about $54 \%, 39 \%, 44 \%$ and $54 \%$ for mothers who reside in the South South relative to mothers in the North Central zone for 2003, 2008, 2013 and 2018 respectively with $P$ values $<0.05$ for each survey year making region of residence a significant determinant of infant mortality. Also, for each of the survey years, being born in urban centres reduced the risk of infant mortality by a minimum of about $30 \%$ with odds of $(0.609$, 0.694, 0.643, 0.703) and P-value $=0.000$ for 2003, 2008, 2013 and 2018 respectively. Improved cultural practises such as using water from clean sources, improved toilet sanitation and use of clean cooking fuel significantly reduced the odds of infant mortality for 2003, 2008, 2013 and 2018 and were all found to be statistically significant determinant of infant mortality with $P$-value $=0.000$.

On mother's education, attaining a minimum of primary education improved the chances of child survival by about 10\%, 48\%, 31\% and 19\% in 2003, 2008, 2013 and 2018 respectively with $P$-values $<0.05$. As the mother's educational level increased prior to child bearing, the chances of infant mortality occurrence reduced (except for higher education in 2013) with mother's education shown to be a significant determinant of infant mortality for each of the survey years. With respect to the place of delivery, mothers who went to the hospital for the delivery of their babies had significantly reduced odds of $0.593,0.449,0.527$ and 0.845 of experiencing childhood mortality in 2003, 2008, 2013 and 2018 respectively compared to women who delivered their babies at home. The place of delivery with a $P$-value $<0.05$ is a significant determinant of infant mortality. The number of antenatal visits of mothers before the delivery of their babies was also found to be a significant determinant of infant mortality with a $P$-value $<0.05$ and an improved survival chance of about $49 \%, 28 \%, 33 \%$ and $58 \%$ for mothers who 
visited the hospital for antenatal on five or more occasions in 2003, 2008, 2013 and 2018 respectively.

Other statistically significant infant mortality variables for each of the survey years are "Breastfeeding" and "Size of child at birth" while infant mortality variables such as "mother's religion", "gender" and "mode of delivery" had $P$-values $>0.05$ for at least one of the survey years implying that they were not statistically significant determinants of infant mortalities for each of the survey years.

Evaluation of the Full Model

(a) Likelihood Ratio Test

Table 7: Result of Likelihood Ratio Test.

\begin{tabular}{|l|c|c|c|c|}
\hline \multirow{2}{*}{ Model } & Model fit measures & \multicolumn{3}{|c|}{ Likelihood Ratio Test } \\
\cline { 2 - 5 } & -2Loglikelihood & Chi-Square & df & Significance \\
\hline Constant Only & 204.670 & 60.461 & 14 & 0.000 \\
Overall model & 144.209 & & & \\
\hline
\end{tabular}

The model fitting measure used is $-2 \log$-likelihood. The value of this criterion for the constant only model was 204.670 while the value of this criterion for the overall model was 144.209. Therefore, value of the likelihood ratio test was computed as follows:

$$
G=204.670-144.209=60.461 .
$$

The hypotheses are that:

$$
\begin{aligned}
& H_{0}: \beta_{1}=\beta_{2}=\cdots=\beta_{14}=0 \\
& H_{1}: \exists \beta_{j} \neq 0, j=1,2, \ldots, 14 .
\end{aligned}
$$

The test indicted that there is at least one of the explanatory variable coefficients that is not equal to zero due to the small p-values being less than 0.05 . As a result of this we reject $H_{0}$ and accept the alternative hypothesis $H_{1}$ and so conclude that at least one of coefficient is not zero.

\section{Receivers Operating Characteristic Curve for full Model}

We use the ROC curve for the classification and predictive accuracy. It was revealed that the area under the ROC curve for the full model is 0.92 . 


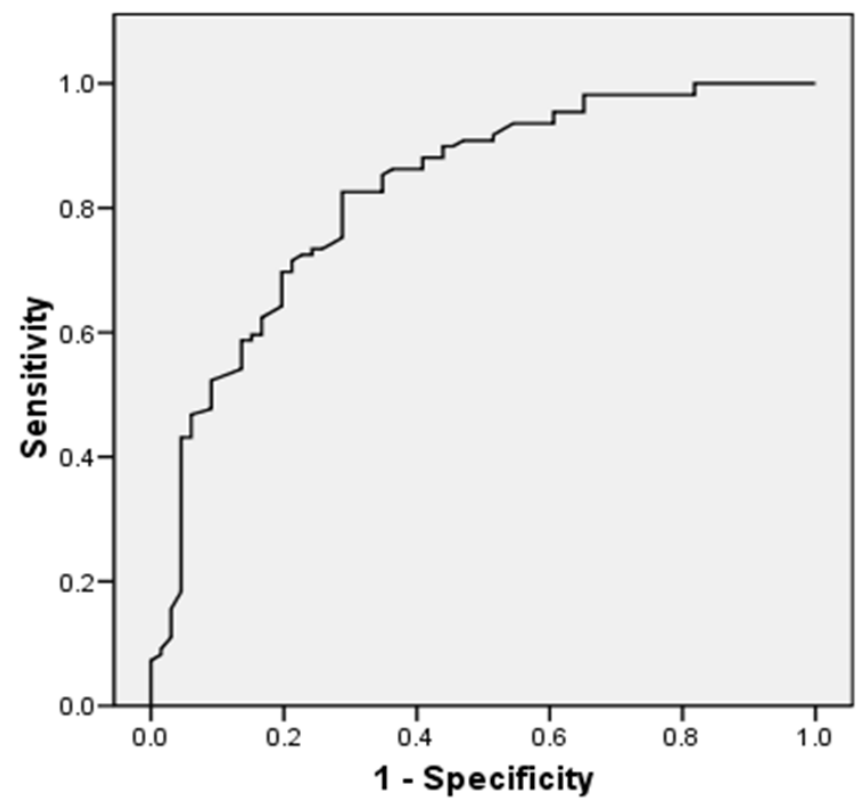

Diagonal segments are produced by ties.

Figure 2: Receiver operating characteristic (ROC) curve for the full model.

\section{(b) Hosmer and Lemeshow Test}

Table 8: Hosmer and Lemeshow Test.

\begin{tabular}{|c|c|c|c|}
\hline Step & Chi-Square & df & Significance \\
\hline 1 & 7.037 & 14 & 0.533 \\
\hline
\end{tabular}

The Hosmer and Lemeshow test above showed a significance of 0.533 implying there is no statistical significance, therefore we fail to reject the null hypothesis that observed and model predicted values are the same. This outcome means the model's estimated values fit the data.

\section{Conclusion}

This study examined the levels, trends and determinants of infant mortality rates in Nigeria using data obtained from consecutive NDHS for 2003, 2008, 2013 and 2018. Logistic regression model was employed to identify the significant determinants of infant mortality for the five years preceding each of the survey. Findings from the study revealed that there is a decline in infant mortality rates over the years but which had 
stagnated in the five year period prior to the 2018 survey with an ARR of $0 \%$ relative to an initial ARR of $5.7 \%$ between 2003 and 2008. Over the course of the 15 year period between 2003 and 2018, the ARR was $2.039 \%$. The study clearly showed that maternal characteristics such as age and educational levels as well as cultural practises like use of clean water and toilet facilities were statistically significant determinants of infant mortality in Nigeria.

\section{Acknowledgment}

We acknowledge the efforts of the National Population Commission, Abuja, Nigeria and other partners involved in the NDHS. We express our appreciation to the National Population Commission and ICF Macro Calverton, Maryland, USA for access to the data used for this study. We are indebted to the anonymous reviewer(s) whose comments and criticism improved the quality of the work.

\section{References}

[1] G. W. Adetoro and E. O. Amoo, A statistical analysis of child mortality: Evidence from Nigeria, Journal of Demography and Social Statistics 1 (2014), 110-120.

[2] D. Antai, Regional inequalities in under-5 mortality in Nigeria: A population-based analysis of individual and community-level determinants, Population Health Metrics 9(6) (2011), 1-27. https://doi.org/10.1186/1478-7954-9-6

[3] E. I. Benchimol, L. Smeeth, A. Guttmann, K. Harron, D. Moher and I. Petersen, The REporting of studies conducted using observational routinely-collected health data (RECORD) statement, PLoS Med. 12(10) (2015), e1001885.

https://doi.org/10.1371/journal.pmed.1001885

[4] R. E. Black and L. I. Liu, Global under five mortality: Where do we stand today?, Johns Hopkins, Bloomberg School of Public Health for the Child Health Epidemiology Reference Group of WHO and UNICEF, 2012.

[5] J. C. Caldwell, Education as a factor in mortality decline: An examination of Nigerian data, Population Studies 33(3) (1979), 395-414. https://doi.org/10.2307/2173888

[6] Q. H. Chowdhury, R. Islam and K. Hossain, Socio-economic determinants of neonatal, post neonatal, infant and child mortality, Int. J. Sociol Anthropol. 27 (2010), 1357-1368.

[7] D. O. Eke and F. Ewere, Modeling and forecasting under-five mortality rate in Nigeria using auto-regressive integrated moving average approach, Earthline Journal of Mathematical Sciences 4(2) (2020), 347-360. https://doi.org/10.34198/ejms.4220.347360 
[8] F. Ewere and D. O. Eke, Neonatal mortality and maternal/child health care in Nigeria: An impact analysis, J. Appl. Sci. Environ. Manage. 24(7) (2020a), 1299-1306. https://dx.doi.org/10.4314/jasem.v24i7.26

[9] F. Ewere and D. O. Eke, Time series analysis and forecast of infant mortality rate in Nigeria: An ARIMA modeling approach, Canadian Journal of Pure and Applied Sciences 14(2) (2020b), 5049-5059.

[10] F. Ewere and D. O. Eke, Analyzing under-five mortality rate trends in Nigeria using the logistic regression model, Transactions of the Nigeria Association of Mathematical Physics 11 (2020c), 131-140. https://doi.org/10.1023/A:1007093631977

[11] R. S. Frey and C. Field, The determinants of infant mortality in the less developed countries: A cross-national test of five theories, Social Indicators Research 52(3) (2000), 215-234. https://doi.org/10.1023/A:1007093631977

[12] K. Hill, D. You, M. Inoue and M. Z. Oestergaard, Technical Advisory Group of the United Nations Inter-agency Group for Child Mortality Estimation, Child mortality estimation: Accelerated progress in reducing global child mortality, 1990-2010, PLoS Med. 9(8) (2012), e1001303. https://doi.org/10.1371/journal.pmed.1001303

[13] B. Masquelier, L. Hug, D. Sharrow, D. You, D. Hogan, K. Hill, J. Liu, J. Pedersen and L. Alkema, Global, regional, and national mortality trends in older children and young adolescents (5-14 years) from 1990 to 2016: an analysis of empirical data, The Lancet Global Health 6(10) (2018), e1087-e1099. https://doi.org/10.1016/S2214-109X(18)30353-X

[14] O. M. Morakinyo and A. F Fagbamigbe, Neonatal, Infant and under-five mortalities in Nigeria: An examination of trends and drivers (2003-2013), PLoS ONE 12(8) (2017), e0182990. https://doi.org/10.1371/journal.pone.0182990

[15] National Bureau of Statistics (NBS) Nigeria, Monitoring the situation of children and women, Nigeria Multiple Indicator Cluster Survey 2011 Summary Report, Abuja, Nigeria: National Bureau of Statistics, 2011.

[16] National Bureau of Statistics (NBS) and United Nations Children's Fund (UNICEF), Multiple Indicator Cluster Survey (MICS) 2016-2017, Survey Findings Report, Abuja, Nigeria: National Bureau of Statistics and United Nations Children's Fund, 2017

[17] National Population Commission (NPC) [Nigeria] and ICF Macro Nigerian Demographic and Health Survey 2008, Abuja, Nigeria: National Population Commission and ICF Macro, 2009.

[18] National Population Commission (NPC) [Nigeria] and ICF, Nigerian Demographic and Health Survey 2018, Abuja, Nigeria and Rockville, Maryland, USA: NPC and ICF, 2019. 
[19] UNICEF Levels and Trends in Child Mortality: Report 2017, Washington, D.C.: World Bank Group, 2017.

http://documents.worldbank.org/curated/en/358381508420391876/levels-and-trends-inchild-mortality-report-2017

[20] UNICEF Levels and Trends in Child Mortality: Report 2018, Estimates Developed by the UN Inter-agency Group for Child Mortality Estimation, 2018.

[21] UN-IGME Levels and Trends in Child Mortality: Report 2019, Estimates Developed by the UN Inter-agency Group for Child Mortality Estimation, United Nations Children's Fund, New York, 2019.

[22] World Health Organization, WHO, Child Mortality: Millennium Development Goal (MDG) 4, The Partner for Maternal and New Born Birth, World Health Organisation, 2011. http://www.who.int/pmnch/media/press_materials/fs/fs_mdg4_childmortality/en/

This is an open access article distributed under the terms of the Creative Commons Attribution License (http://creativecommons.org/licenses/by/4.0/), which permits unrestricted, use, distribution and reproduction in any medium, or format for any purpose, even commercially provided the work is properly cited. 